\title{
Rapid Detection of Gut Microbial Metabolite Trimethylamine N-Oxide for Chronic Kidney Disease Prevention
}

\author{
Yu-Chun Chang ${ }^{1}$, Yi-Hsuan Chu ${ }^{2}$, Chien-Cheng Wang ${ }^{2}$, Chih-Hsuan Wang ${ }^{3}{ }^{\mathbb{D}}$, You-Lin Tain ${ }^{4,5}, * \mathbb{C}$ \\ and Hung-Wei Yang $1, * \mathbb{B}$ \\ 1 Institute of Medical Science and Technology, National Sun Yat-Sen University, Kaohsiung 804201, Taiwan; \\ adamycchang@gmail.com \\ 2 Saint Dominic Catholic High School, Kaohsiung 802306, Taiwan; jolenechu@nsysumel.com (Y.-H.C.); \\ pcjason11@gmail.com (C.-C.W.) \\ 3 Department of Internal Medicine, Kaohsiung Armed Forces General Hospital, Kaohsiung 802301, Taiwan; \\ wangchihhsuan@gmail.com \\ 4 Department of Pediatrics, College of Medicine, Kaohsiung Chang Gung Memorial Hospital, \\ Chang Gung University, Kaohsiung 833401, Taiwan \\ 5 Institute for Translational Research in Biomedicine, College of Medicine, Kaohsiung Chang Gung Memorial \\ Hospital, Chang Gung University, Kaohsiung 833401, Taiwan \\ * Correspondence: tainyl@cgmh.org.tw (Y.-L.T.); howardyang@mail.nsysu.edu.tw (H.-W.Y.)
}

\section{check for}

updates

Citation: Chang, Y.-C.; Chu, Y.-H.; Wang, C.-C.; Wang, C.-H.; Tain, Y.-L.; Yang, H.-W. Rapid Detection of Gut Microbial Metabolite Trimethylamine N-Oxide for Chronic Kidney Disease Prevention. Biosensors 2021, 11, 339. https://doi.org/10.3390/bios11090339

Received: 20 August 2021

Accepted: 10 September 2021

Published: 14 September 2021

Publisher's Note: MDPI stays neutral with regard to jurisdictional claims in published maps and institutional affiliations.

Copyright: (C) 2021 by the authors. Licensee MDPI, Basel, Switzerland. This article is an open access article distributed under the terms and conditions of the Creative Commons Attribution (CC BY) license (https:/ / creativecommons.org/licenses/by/ $4.0 /)$.

\begin{abstract}
The gut microbiota plays a critical role in chronic kidney disease (CKD) and hypertension. Trimethylamine-N-oxide (TMAO) and trimethylamine (TMA) are gut microbiota-derived metabolites, and both are known uraemic toxins that are implicated in $\mathrm{CKD}$, atherosclerosis, colorectal cancer and cardiovascular risk. Therefore, the detection and quantification of TMAO, which is a metabolite from gut microbes, are important for the diagnosis of diseases such as atherosclerosis, thrombosis and colorectal cancer. In this study, a new "colour-switch" method that is based on the combination of a plasma separation pad/absorption pad and polyallylamine hydrochloride-capped manganese dioxide $\left(\mathrm{PAH} @ \mathrm{MnO}_{2}\right)$ nanozyme was developed for the direct quantitative detection of TMAO in whole blood without blood sample pretreatment. As a proof of concept, a limit of quantitation (LOQ) of less than $6.7 \mu \mathrm{M}$ for TMAO was obtained with a wide linear quantification range from 15.6 to $500 \mu \mathrm{M}$ through quantitative analysis, thereby suggesting potential clinical applications in blood TMAO monitoring for CKD patients.
\end{abstract}

Keywords: nanoenzyme; trimethylamine N-oxide (TMAO); gut microbiota; colorimetry; chronic kidney disease (CKD)

\section{Introduction}

Chronic kidney disease (CKD) is a highly prevalent disease that affects nearly $10 \%$ of the world's population [1]. There is increasing evidence that trimethylamine N-oxide (TMAO) is among the critical metabolites of gut bacteria, and it has been found to be associated with adverse cardiac events and CKD [2]. It is a key biomarker for a wide variety of human cardiac and kidney diseases [3] and was recently identified as a biomarker for colorectal cancer [4]. In people, TMAO is mostly eliminated from the body through urine and sweat [5]. Since the main clearance of TMAO from the body is through urine [6], a real clinical demand remains for new methods for rapidly detecting TMAO in serum or urine for the diagnosis and risk prediction of clinical diseases, such as CKD $[7,8]$.

The commonly used methods for TMAO quantification are GC- and LC-MS/MS [9,10] and ${ }^{1} \mathrm{H}$ NMR [11] techniques that generally require complicated and laborious procedures, long analysis times, specially trained personnel, and costly analytical instruments that are not widely available in clinical diagnostic laboratories. To address these issues, the development of a simple, inexpensive and rapid analytical method for TMAO detection is urgently needed. Wollenberger et al. reported an electrochemical biosensor for TMAO 
detection that uses TMAO reductase, namely, TorA, which specifically catalyses the reduction of TMAO to trimethylamine (TMA) [12], followed by the measurement of the resulting current using direct electrochemistry to quantify the concentration of TMAO [13]. However, its practical application has been limited due to the need to separate amine analytes and the lack of simplicity, efficiency, and portability of these reductions. Wang and coworkers explored a facile fluorescence assay for TMAO quantification on the basis of an indicator displacement assay (IDA) using water-soluble guanidinium-modified calix [5] arene (GC5A) as an artificial receptor [14]. However, its practical application has been limited because the indicator displacement may be affected by other substances in real urine samples.

Recently, researchers have increasingly paid attention to colourimetric array-based sensors in the biomedical biosensing field. Colourimetric sensors differ fundamentally from traditional electronic sensors in that the sensor signals depend not on physical sorption of analyte molecules (changes in the current) but instead on strong chemical interactions to change the colour (UV-vis absorption) [15]. Li and Suslick designed new nanostructured materials as colourimetric sensors for the specific detection of volatile amines [16]. However, the method requires an airtight container, the delivery of 13 inks on a polypropylene membrane, and the separation of other amine analytes, which limits its application for point-of-care (PoC) TMAO tests.

From the viewpoint of analytical science and with the above considerations, we demonstrated a new colourimetric assay for the rapid detection of TMAO with a simple procedure in which polyallylamine hydrochloride-capped manganese dioxide nanoparticles (PAH@MnO $\mathrm{Mn}_{2} \mathrm{NPs}$ ) are used as reaction promoters and peroxidase mimics (Scheme 1A). We found that protons (from $\mathrm{HCl}$ ) would be depleted during TMAO reduction, which would reduce the formation of diimine end products from TMB by PAH@MnO $\mathrm{NPs}_{2}$ to increase the absorbance intensity at $650 \mathrm{~nm}\left(\mathrm{~A}_{650}\right)$ (Scheme 1B). The quantitative detection of TMAO was realised within the biological range without sample pretreatment, and excellent performance was demonstrated; thus, this assay has potential clinical applications in CKD PoC.

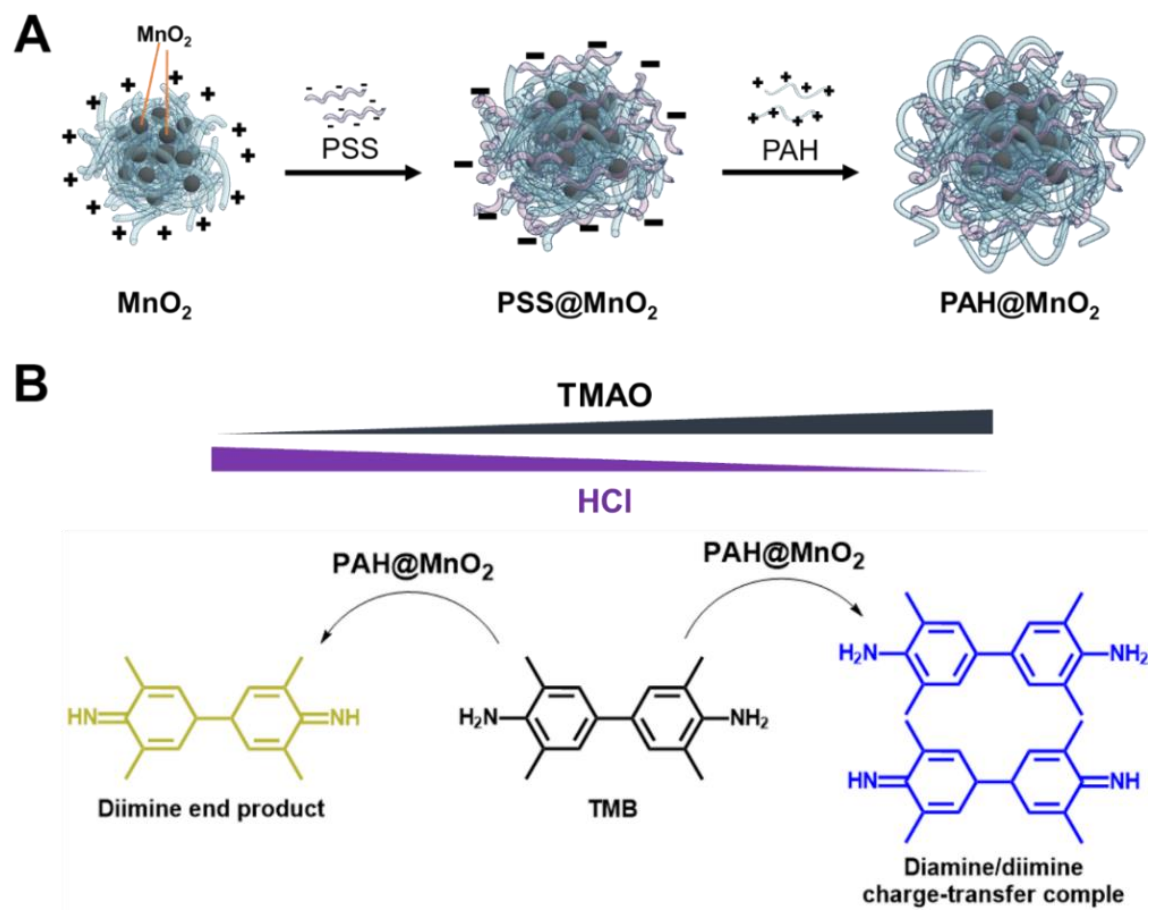

Scheme 1. (A) An illustration of $\mathrm{PAH} @ \mathrm{MnO}_{2}$ synthesis; (B) the design and principle of colourimetric TMAO detection based on proton deposition of $\mathrm{HCl}$ by TMAO. 


\section{Experimental Section}

\subsection{Materials}

All chemical reagents, which included trimethylamine-N-oxide (TMAO), polyallylamine hydrochloride (PAH, Mw 17,500 Da), polysodium 4-styrenesulfonate (PSS, Mw $70,000 \mathrm{Da})$, potassium permanganate, hydrogen chloride $(\mathrm{HCl})$, sodium chloride $(\mathrm{NaCl})$, $3,3^{\prime}, 5,5^{\prime}$-tetramethylbenzidine (TMB), and hydrogen peroxide $\left(\mathrm{H}_{2} \mathrm{O}_{2}\right)$, were purchased from Sigma-Aldrich.

\subsection{Preparation of $\mathrm{PAH}$-Capped $\mathrm{MnO}_{2} \mathrm{NPs}$ ( $\mathrm{PAH} @ \mathrm{MnO}_{2} \mathrm{NPs}_{\mathrm{s}}$ )}

$\mathrm{PAH} @ \mathrm{MnO}_{2} \mathrm{NPs}$ were prepared by directly mixing aqueous solutions of $\mathrm{KMnO}_{4}$ and PAH. Briefly, $1 \mathrm{~mL}$ of PAH solution $(1 \mathrm{mg} / \mathrm{mL})$ that contained $0.1 \mathrm{M} \mathrm{NaCl}$ was mixed with $15 \mu \mathrm{L}$ of $\mathrm{KMnO}_{4}$ solution $(27.6 \mathrm{mg} / \mathrm{mL})$, and the mixture was left for $20 \mathrm{~min}$ at room temperature until all permanganate was converted to $\mathrm{MnO}_{2} . \mathrm{MnO}_{2}$ formation was confirmed by observing with the naked eye a colour change to brown from purple. Subsequently, $\mathrm{MnO}_{2} \mathrm{NPs}$ were added to PSS solution $(1 \mathrm{mg} / \mathrm{mL}, 0.1 \mathrm{M} \mathrm{NaCl})$ in equal volume and shaken for 10 min to form PSS-capped $\mathrm{MnO}_{2} \mathrm{NPs}$, which were centrifuged $(12,000 \mathrm{rpm}$ for $15 \mathrm{~min})$ to remove the unreacted chemicals. Then, the precipitate was resuspended in PAH solution $(1 \mathrm{mg} / \mathrm{mL}, 0.1 \mathrm{M} \mathrm{NaCl})$ and shaken for $30 \mathrm{~min}$. The mixture was washed three times with $\mathrm{DI}-\mathrm{H}_{2} \mathrm{O}$ using centrifugation to obtain $\mathrm{PAH} @ \mathrm{MnO}_{2} \mathrm{NPs}$.

\subsection{Stability Tests}

HRP and PAH@MnO $\mathrm{MPs}_{2}$ were stored in a vacuum dry oven at 25 and $50{ }^{\circ} \mathrm{C}$. After storage for various periods (1-60 days), the stored HRP and PAH@MnO $\mathrm{NPs}_{2}$ were used to catalyse $\mathrm{H}_{2} \mathrm{O}_{2} / \mathrm{TMB}$ and showed an absorption intensity of $450 \mathrm{~nm}\left(\mathrm{~A}_{450 \mathrm{~nm}}\right)$ after the addition of $\mathrm{HCl}$. The activities of the stored HRP and $\mathrm{PAH} @ \mathrm{MnO}_{2} \mathrm{NPs}$ were determined by comparing their $\mathrm{A}_{450 \mathrm{~nm}}$ values with their initial $\mathrm{A}_{450 \mathrm{~nm}}$ values at Day 0 . All measurements were performed in triplicate for accurate calculations to develop a standard protocol.

\section{4. $p H$ Effect on the Peroxidation Activity}

The peroxidation activities of HRP and PAH@MnO 2 NPs towards $\mathrm{H}_{2} \mathrm{O}_{2} / \mathrm{TMB}$ at various $\mathrm{pH}$ values ( $\mathrm{pH} 3$ to $\mathrm{pH} 11$ ) were analysed at $25^{\circ} \mathrm{C}$. The activities were determined by measuring $\mathrm{A}_{450 \mathrm{~nm}}$ after the addition of $\mathrm{HCl}$. All measurements were performed in triplicate for accurate calculations to develop a standard protocol.

\subsection{Colourimetric Detection of TMAO}

For the detection process, various concentrations of TMAO $(100 \mu \mathrm{L})$, which ranged from 15.6 to $1000 \mu \mathrm{M}$, were mixed with $20 \mu \mathrm{L} \mathrm{HCl}$ and $20 \mu \mathrm{L}$ PAH@MnO $\mathrm{NPs}_{2}$ for 3 min at room temperature. Subsequently, $20 \mu \mathrm{L}$ of the above mixture was drawn out and mixed with $100 \mu \mathrm{L}$ of $\mathrm{TMB} / \mathrm{H}_{2} \mathrm{O}_{2}$ solution. Finally, the colour of the solution changed to light blue from yellow with increasing TMAO concentration, and the results were recorded by a SpectraMax M2 spectrometer to obtain $\mathrm{A}_{650}$. The $\mathrm{A}_{650}$ values were linearly proportional to the concentration of TMAO in a linear detection range. All experiments were conducted in sextuplicate for precise calculations to develop a standard protocol.

\subsection{Preparation of an Artificial Urine Solution}

An artificial urine solution was prepared according to previous reports [14,17], namely, by dissolving urea $(9.1 \mathrm{~g})$, sodium chloride $(3.7 \mathrm{~g})$, sodium phosphate (monobasic, $2.4 \mathrm{~g}$ ), potassium chloride $(2.2 \mathrm{~g})$, creatinine $(1.0 \mathrm{~g})$ and BSA $(25 \mathrm{mg})$ in $500 \mathrm{~mL} \mathrm{DI}-\mathrm{H}_{2} \mathrm{O}$. The $\mathrm{pH}$ of the artificial urine solution was adjusted to $\mathrm{pH} 6.0$ with $\mathrm{HCl}$ and stored at $4{ }^{\circ} \mathrm{C}$. Subsequently, the artificial urine was spiked with various concentrations of TMAO (100, 250 , and $500 \mu \mathrm{M})$ for recovery tests. The detection procedure was the same as in Section 2.5. 


\subsection{TMAO Rapid Detection in Plasma from CKD Rats}

All animal studies were approved by the Institutional Animal Ethics Committee (IACUC) of Chang Gung Memorial Hospital (permit number 2020031602). For the samples, 16 female Sprague Dawley (SD) rats were purchased from BioLASCO Taiwan Co., Ltd. (Taipei, Taiwan).

At six weeks of age, rats of both sexes received a regular diet (Normal group, 8 rats) or a diet that was supplemented with $0.5 \%$ adenine $(0.25 \mathrm{mg} / \mathrm{kg} /$ day) for three weeks (CKD group, 8 rats). The dose was selected based on our previous studies in rats [18]. At nine weeks of age, the rats were sacrificed to collect heparinised blood samples. The plasma TMAO concentration was determined by liquid chromatography-mass spectrometry (LCMS) using previously described methods [19]. The TMAO concentration in the blood of each rat was also determined by the proposed colourimetric assay. First, a drop of blood was dropped on a plasma separation pad that covered an absorption pad. Then, the filtered solution (serum or plasma) was sucked into the absorbent pad and put into a well of a 96-well plate that contained $100 \mu \mathrm{L}$ of $\mathrm{H}_{2} \mathrm{O}, 20 \mu \mathrm{L}$ of $\mathrm{HCl}$ and $20 \mu \mathrm{L}$ of $\mathrm{PAH} @ \mathrm{MnO}_{2}$ NPs at room temperature. Subsequently, $20 \mu \mathrm{L}$ of the above mixture was drawn out and mixed with $100 \mu \mathrm{L}$ of $\mathrm{TMB} / \mathrm{H}_{2} \mathrm{O}_{2}$ solution. The obtained value of $\mathrm{A}_{650}$ was recorded to determine the TMAO concentration in the whole blood of normal/or CKD rats using the respective calibration curves for the colourimetric assay with the SpectraMax M2 spectrometer. Animal care and experiments were conducted according to established guidelines for the care and use of laboratory animals.

\subsection{Statistics}

The data are expressed as the mean $\pm \mathrm{SD}$ on the basis of at least three independent experiments. Statistical analysis was performed using Student's $t$-test. Differences were considered statistically significant if $* p<0.05$.

\section{Results and Discussion}

\subsection{Characterisation of the PAH@MnO $\mathrm{N}_{2} \mathrm{NP}$}

The synthesis of $\mathrm{PAH} @ \mathrm{MnO}_{2} \mathrm{NPs}$ was conducted according to a reported procedure with some modifications [20]. Typically, $\mathrm{MnO}_{2} \mathrm{NPs}$ were prepared by reducing $\mathrm{KMnO}_{4}$ to $\mathrm{MnO}_{2}$ with cationic PAH. As shown in Figure 1A, the main peak of $\mathrm{KMnO}_{4}$ at $526 / 546 \mathrm{~nm}$ disappeared, but a new peak at $352 \mathrm{~nm}$ that corresponded to $\mathrm{MnO}_{2} \mathrm{NPs}$ appeared after $\mathrm{MnO}_{2}$ formation, thereby demonstrating that $\mathrm{KMnO}_{4}$ was successfully reduced to form $\mathrm{MnO}_{2}$ with cationic PAH [21]. This result was also confirmed by a colour change (from purple to brown, Figure $1 \mathrm{~A}$ inset). To stabilise $\mathrm{MnO}_{2}$, we deposited polyelectrolytes on the surface of $\mathrm{MnO}_{2}$. After deposition of PSS, the zeta potential of PSS@MnO 2 was reduced to $-56.8 \pm 3.6 \mathrm{mV}$ from $18.6 \pm 4.6 \mathrm{mV}$ because the attached PSS has a mass of carboxyl groups on the external surface. After self-assembly with PAH to form $\mathrm{PAH} @ \mathrm{MnO}_{2}$, the zeta potential further changed to $43.8 \pm 2.3 \mathrm{mV}$, which enabled $\mathrm{PAH} @ \mathrm{MnO}_{2}$ to disperse in a water well (Figure 1B). The PAH@ $\mathrm{MnO}_{2}$ NPs were stable and dispersed well in DI$\mathrm{H}_{2} \mathrm{O}$ with an average diameter of $158.6 \mathrm{~nm}$ after PSS and PAH layer-by-layer assembly (Figure 1C). Transmission electron microscopy (TEM) images showed that the PAH@MnO NPs established prominent size uniformity and dispersibility in the form of a walnut-like shape (Figure 1C, inset). 

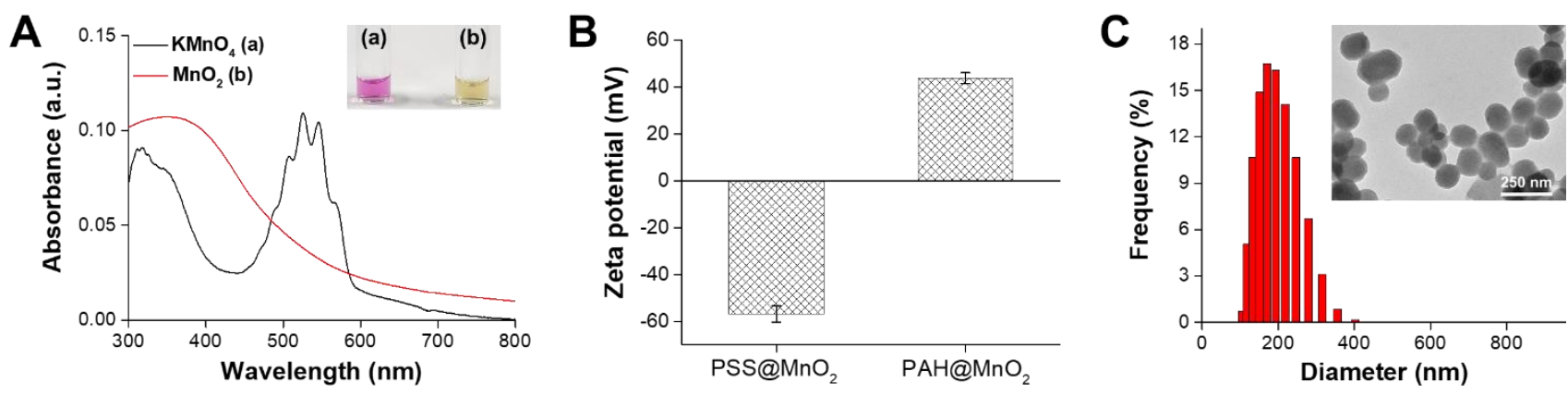

Figure 1. (A) UV-vis absorption spectra of $\mathrm{KMnO}_{4}$ and $\mathrm{MnO}_{2}$ in $\mathrm{DI}-\mathrm{H}_{2} \mathrm{O}$; the inset is a corresponding digital photo. (B) Zeta potential values of PSS@MnO 2 and $\mathrm{PAH} @ \mathrm{MnO}_{2}(n=3)$. (C) Dynamic light scattering (DLS) analysis results of $\mathrm{PAH}_{\mathrm{M}} @ \mathrm{MnO}_{2}$ NPs; the inset shows the corresponding TEM.

\subsection{Mechanism of TMAO Detection Using PAH@MnO $\mathrm{NPS}_{2}$}

In this study, we created a simple colourimetric assay for analysing TMAO by evaluating the oxidation level of TMB in the presence of $\mathrm{H}_{2} \mathrm{O}_{2}$ using PAH@MnO 2 NPs as nanozymes. As shown in Figure 2A, neither TMAO nor $\mathrm{HCl}$ oxidised TMB in the presence of $\mathrm{H}_{2} \mathrm{O}_{2}$ to cause a colour change. In contrast, $\mathrm{PAH} @ \mathrm{MnO}_{2} \mathrm{NPs}$ could oxidise TMB in the presence of $\mathrm{H}_{2} \mathrm{O}_{2}$ to form a diamine/diimine charge-transfer complex and induce a new peak at $650 \mathrm{~nm}$ (blue colour, curve (b). In the presence of $\mathrm{HCl}$, the produced diamine/diimine charge-transfer complex further changed to a diimine end product. The main peak at $650 \mathrm{~nm}$ disappeared, but a new peak at $450 \mathrm{~nm}$ appeared (yellow colour, curve (a). The results demonstrated that the amount of $\mathrm{HCl}$ affected the ratio between the diamine/diimine charge-transfer complex and the diimine end product after TMB oxidation. To further prove that TMAO could deplete $\mathrm{HCl}$, the change in $\mathrm{A}_{650}$ was investigated. As shown in Figure 2B, $A_{650}$ increased and the absorbance intensity at $450 \mathrm{~nm}\left(\mathrm{~A}_{450}\right)$ decreased in the presence of TMAO, thereby indicating that TMAO could deplete $\mathrm{HCl}$ to reduce the production of the diamine end product. Thus, the detection of TMAO is feasible using the developed colourimetric analysis.
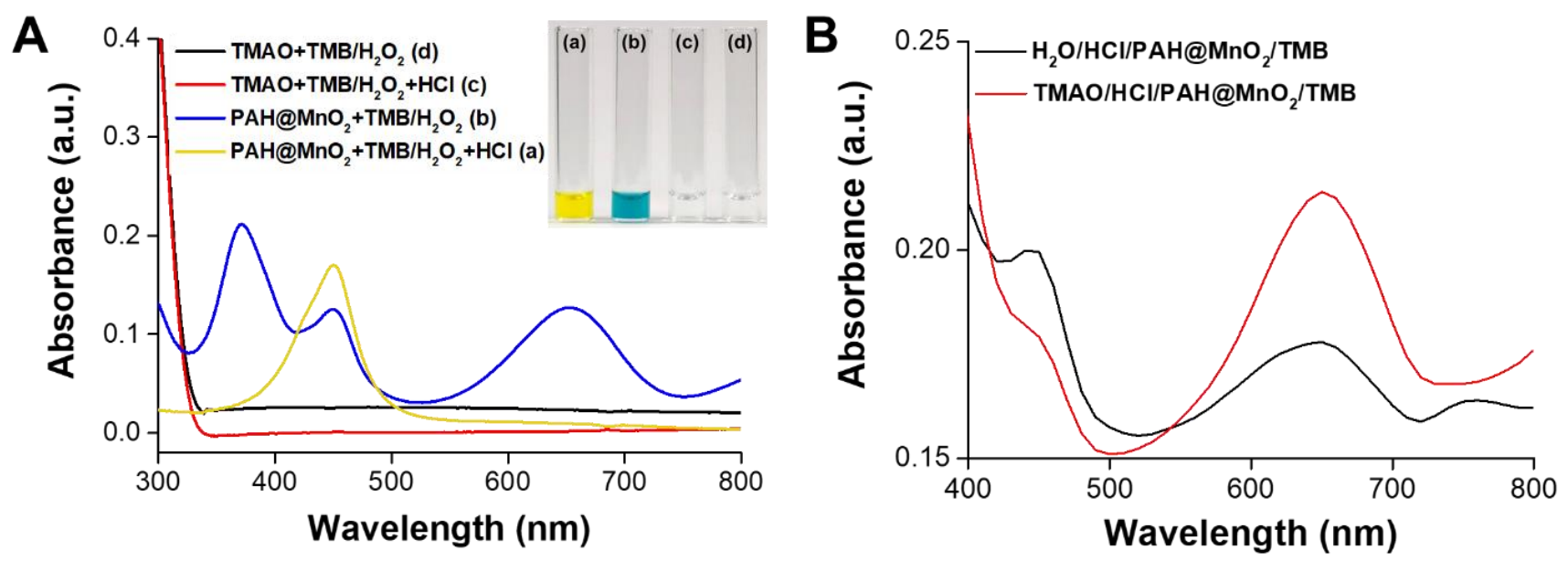

Figure 2. (A) UV-vis absorption spectra and visual colour changes of the catalysed oxidation of TMB in the absence or presence of $\mathrm{PAH} @ \mathrm{MnO}_{2}$; the inset is a corresponding digital photo; (B) UV-vis absorption spectra of the catalysed oxidation of TMB in the absence or presence of TMAO to prove the mechanism of proton depletion by TMAO.

\subsection{Comparison of PAH@MnO 2 and HRP in Terms of Peroxidation Activity and Stability}

Most relevant studies in the literature have indicated the high peroxidation activity of an $\mathrm{HRP}$ weak acid environment towards TMB oxidation in the presence of $\mathrm{H}_{2} \mathrm{O}_{2}$; however, it may not be suitable for bioassays in any environment. Thus, a series of PBS solutions with $\mathrm{pH}$ values that varied from 3 to 11 were prepared to explore the effects of $\mathrm{pH}$ on HRP 
and PAH@MnO $\mathrm{M}_{2}$. The results in Figure 3A indicate that the peroxidation activity of HRP is sensitive to $\mathrm{pH}$, and the optimal result was obtained at a $\mathrm{pH}$ of 6 ; the activity significantly decreased when the $\mathrm{pH}$ was higher or lower than 6 . In contrast, the peroxidation activity of $\mathrm{PAH} @ \mathrm{MnO}_{2}$ was not affected by the $\mathrm{pH}$; the artificial enzyme $\mathrm{PAH} @ \mathrm{MnO}_{2}$ could effectively oxidise TMB in the presence of $\mathrm{H}_{2} \mathrm{O}_{2}$ to produce a consistent signal over a wide $\mathrm{pH}$ range from 3-11, thereby indicating that $\mathrm{PAH} @ \mathrm{MnO}_{2}$ is more suitable than HRP for the bioassay of clinical samples. The most common and severe problem that is encountered with enzyme-based biosensors is their lack of stability, which is due to the intrinsic nature of the enzyme. Thus, we evaluated the long-term stabilities of $\mathrm{HRP}$ and $\mathrm{PAH} @ \mathrm{MnO}_{2}$ after periods of storage of between 1 and 60 days at 25 and $50{ }^{\circ} \mathrm{C}$; the responses were monitored by reacting TMB with HRP and $\mathrm{PAH} @ \mathrm{MnO}_{2}$ at each time point in the presence of $\mathrm{H}_{2} \mathrm{O}_{2}$. As shown in Figure 3B, HRP lost all its activity after 7 days of storage at $50^{\circ} \mathrm{C}$ and did not maintain its activity beyond 23 days of storage at $25^{\circ} \mathrm{C}$. Impressively, $\mathrm{PAH} @ \mathrm{MnO}_{2}$ maintained its complete peroxidation activity without any decay, even when stored at 25 or $50{ }^{\circ} \mathrm{C}$ for 60 days. Based on these data, the peroxidase-mimicking $\mathrm{PAH} @ \mathrm{MnO}_{2}$ nanozyme that is described herein presents high oxidisation activity to TMB in the presence of $\mathrm{H}_{2} \mathrm{O}_{2}$, strong thermal stability, and low cost; hence, it is suitable for replacing HRP as the signal for colourimetric immunosensing.
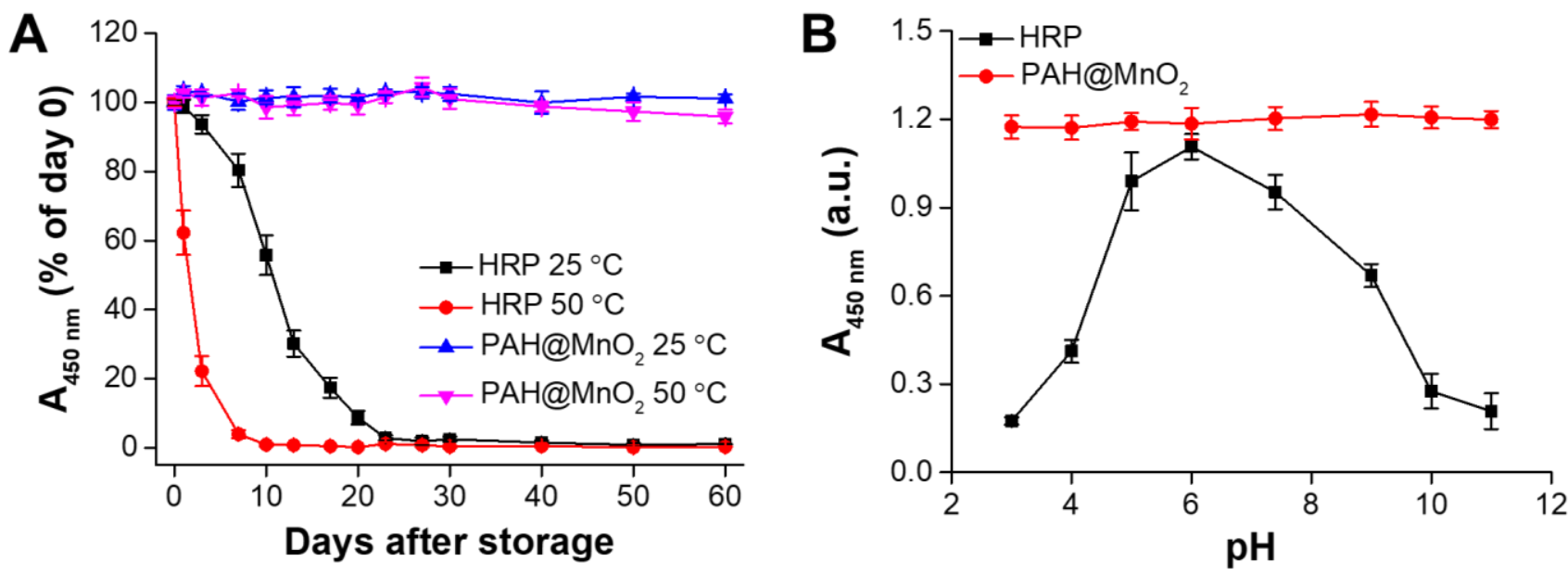

Figure 3. (A) The stabilities of $\mathrm{HRP}$ and $\mathrm{PAH} @ \mathrm{MnO}_{2}$ after storage at 25 and $50{ }^{\circ} \mathrm{C}$ for periods of $1-60$ days. $\mathrm{PAH} @ \mathrm{MnO}_{2}$ showed no decrease in oxidisability towards $\mathrm{H}_{2} \mathrm{O}_{2} / \mathrm{TMB}$ after 60 days of storage at $50{ }^{\circ} \mathrm{C}$. The values are means $\pm \mathrm{SD}$ $(n=3)$; (B) the absorbances at $450 \mathrm{~nm}$ of $\mathrm{HRP}$ and $\mathrm{PAH} @ \mathrm{MnO}_{2}$ in the presence $\mathrm{H}_{2} \mathrm{O}_{2} / \mathrm{TMB}$ in PBS with various $\mathrm{pH}$ levels. The values are means $\pm \operatorname{SD}(n=3)$.

\subsection{Colourimetric Analysis of TMAO}

To the best of our knowledge, LC-MS has been widely utilised to determine TMAO thus far with a wide linear detection range $(10 \mu \mathrm{M} \sim 3000 \mu \mathrm{M})$ and a limit of quantitation (LOQ) of $5 \mu \mathrm{M}$; however, a stable isotopically labelled standard has been employed, which requires synthetic stable isotope markers, specially trained personnel, and specialised and costly analytical instruments, thereby limiting its clinical utilisation [22]. Consequently, semiquantifying TMAO in humour (especially in blood) has become an indispensable and urgent clinical task that facilitates the early diagnosis of CKD. In this study, we hypothesise that protons will be taken up during TMAO reduction to TMA in the presence of a catalyst that will reduce the formation of the diimine end product from TMB by $\mathrm{PAH} @ \mathrm{MnO}_{2} \mathrm{NPs}$ to increase the value of $A_{650}$. From the results in Figure $4 A, A_{650}$ increased with increasing concentration of TMAO, and the standard curve was found to be linear in the range of 15.6 to $500 \mu \mathrm{M}$ and a LOQ of $6.7 \mu \mathrm{M}$ for TMAO when PAH@ $\mathrm{MnO}_{2}$ NPs were used as the catalyst $\left(\mathrm{r}^{2}=0.997\right.$; Figure $\left.4 \mathrm{~B}\right)$. Even though its linear detection range and LOQ are not 
superior to LC-MS, it has the advantage of simple, rapid and low-cost TMAO detection, which has potential clinical applications in CKD PoC.
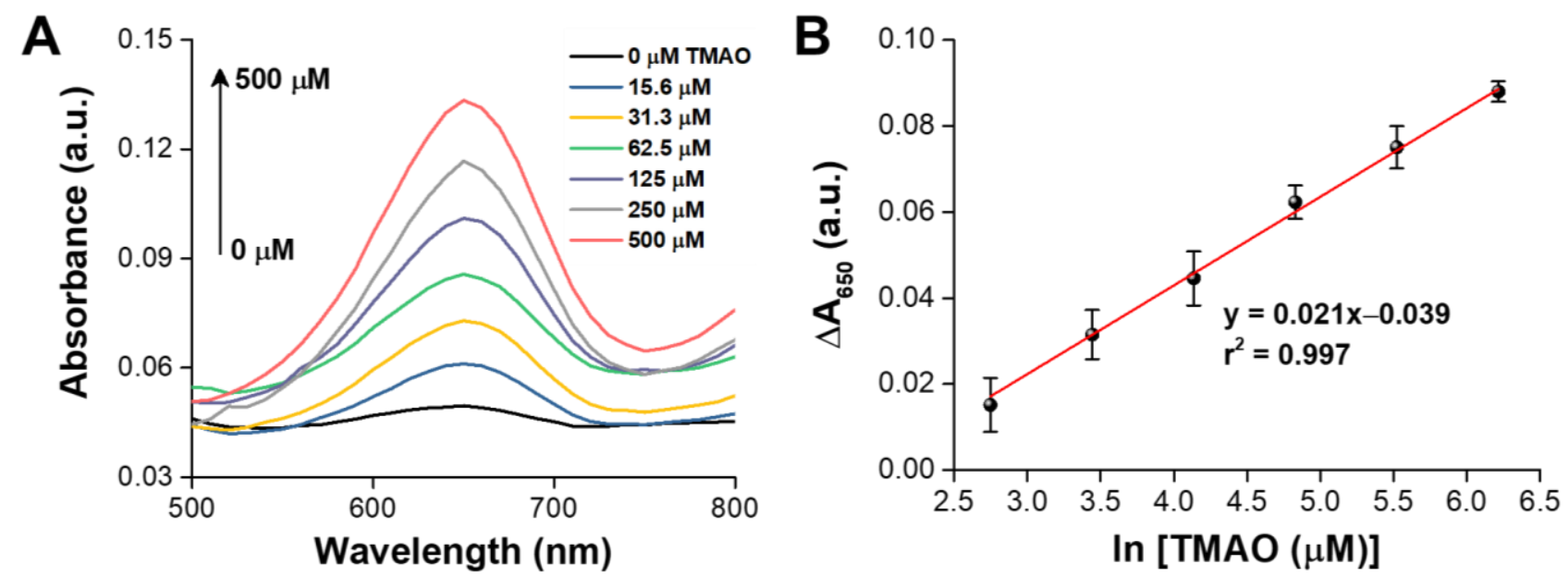

Figure 4. (A) Typical UV-vis absorption spectra of TMB for the detection of TMAO at various concentrations using the colour-switch method based on PAH@ $\mathrm{MnO}_{2} ;(\mathbf{B})$ the linear calibration curve between $\mathrm{A}_{650}$ and the TMAO concentration. The values are means $\pm \mathrm{SD}(n=6)$.

\subsection{Recovery of TMAO in Spiked Urine Samples}

To prove the specificity and accuracy of our rapid detection of TMAO, we spiked various concentrations of TMAO into artificial urine, which ranged from 100 to $500 \mu \mathrm{M}$, and the $\mathrm{A}_{650}$ values were recorded by a spectrophotometer; the results are presented in Table 1. The recovery rates of TMAO were found to be acceptable and in the range of $97-102 \%$, and the relative standard deviation was lower than $8 \%$, thereby indicating that our TMAO rapid detection is accurate enough for TMAO detection without any interference.

Table 1. Determination of spiked TMAO in artificial urine samples using the proposed colourimetric assay, which is based on the $\mathrm{PAH} @ \mathrm{MnO}_{2}$ nanozyme.

\begin{tabular}{cccc}
\hline Sample & $\begin{array}{c}\text { Spiked Concentration } \\
(\boldsymbol{\mu M})\end{array}$ & $\begin{array}{c}\text { Detected } \\
(\boldsymbol{\mu M})\end{array}$ & $\begin{array}{c}\text { Recovery } \\
(\mathbf{\%})\end{array}$ \\
\hline \multirow{3}{*}{ Artificial urine } & 100 & $101.7 \pm 7.2$ & $101.7 \pm 7.2$ \\
& 300 & $303.4 \pm 8.9$ & $101.1 \pm 3.0$ \\
\hline
\end{tabular}

\subsection{TMAO Rapid Detection in Plasma from CKD Rats}

Although it is easier to detect TMAO in a urine sample than in a blood sample, the concentration of TMAO in the urine of patients is easily affected by the amount of water they drink. However, if we were to directly measure the TMAO concentration in the blood using a colourimetric assay, the detection accuracy would be affected by the colour of the blood. In light of this, we designed a plasma separation pad that was coated with PEG8000 as an erythrocyte trap to retain and filter erythrocytes and haemachrome. Then, the filtered solution (possibly serum or plasma) was sucked into the absorbent pad for colourimetric assay of TMAO in fingertip blood (Figure 5A). Furthermore, we confirmed that the absorbent pad with serum/or plasma did not deplete the protons from $\mathrm{HCl}$ by observing a weak absorption peak at $650 \mathrm{~nm}$, which was the same as for the PBS group. Conversely, a strong absorption peak at $650 \mathrm{~nm}$ was observed in the presence of $30 \mu \mathrm{M}$ TMAO, thereby indicating that the protons from $\mathrm{HCl}$ were indeed depleted by $\mathrm{TMAO}$ to reduce the formation of the diimine end product from TMB by PAH@MnO 2 NPs (Figure 5B). The results also demonstrated that the proposed colourimetric assay can be used for simple and rapid TMAO detection in fingertip blood. Finally, the feasibility and performance 
of the proposed colourimetric TMAO assay in CKD rats without sample pretreatment were studied. First, a drop of whole blood $(\sim 20 \mu \mathrm{L})$ from a CKD rat was dropped onto a plasma separation pad that covered an absorption pad to prevent colour interruption in the proposed colourimetric assay. Then, the absorption pad was put into a well of a 96-well plate that contained $100 \mu \mathrm{L}$ of $\mathrm{H}_{2} \mathrm{O}, 20 \mu \mathrm{L}$ of $\mathrm{HCl}$ and $20 \mu \mathrm{L}$ of $\mathrm{PAH} @ \mathrm{MnO}_{2}$ NPs at room temperature. Subsequently, $20 \mu \mathrm{L}$ of the above mixture was drawn out and mixed with $100 \mu \mathrm{L}$ of $\mathrm{TMB} / \mathrm{H}_{2} \mathrm{O}_{2}$ solution. A total of 16 whole blood samples ( 8 from normal rats and 8 from CKD rats) were used to assess the feasibility of our PAH@ $\mathrm{MnO}_{2}$ NP-based colourimetric TMAO assay. Furthermore, the results were compared with those that were obtained using LC-MS, and no significant difference was found between them (Figure 5C). The results indicated that the accuracy of the proposed colourimetric assay for TMAO detection is comparable to that of LC-MS, but it is simpler and faster for daily CKD monitoring.

To understand whether the metabolites in the blood after eating or taking medication will affect the accuracy of TMAO detection using the proposed colourimetric assay, we detected the TMAO concentrations in blood from the rats that had been given $0.1 \mathrm{~mL}$ PBS (three rats), ascorbic acid (200 mg/mL, three rats), glucose (200 mg/mL, three rats), and sodium thiosulfate $(200 \mathrm{mg} / \mathrm{mL}$, three rats) for $24 \mathrm{~h}$. The results demonstrated no significant difference between four groups, indicating that the metabolites in blood after diet or medication would not affect the accuracy of the proposed colourimetric assay for TMAO detection (Figure S1).
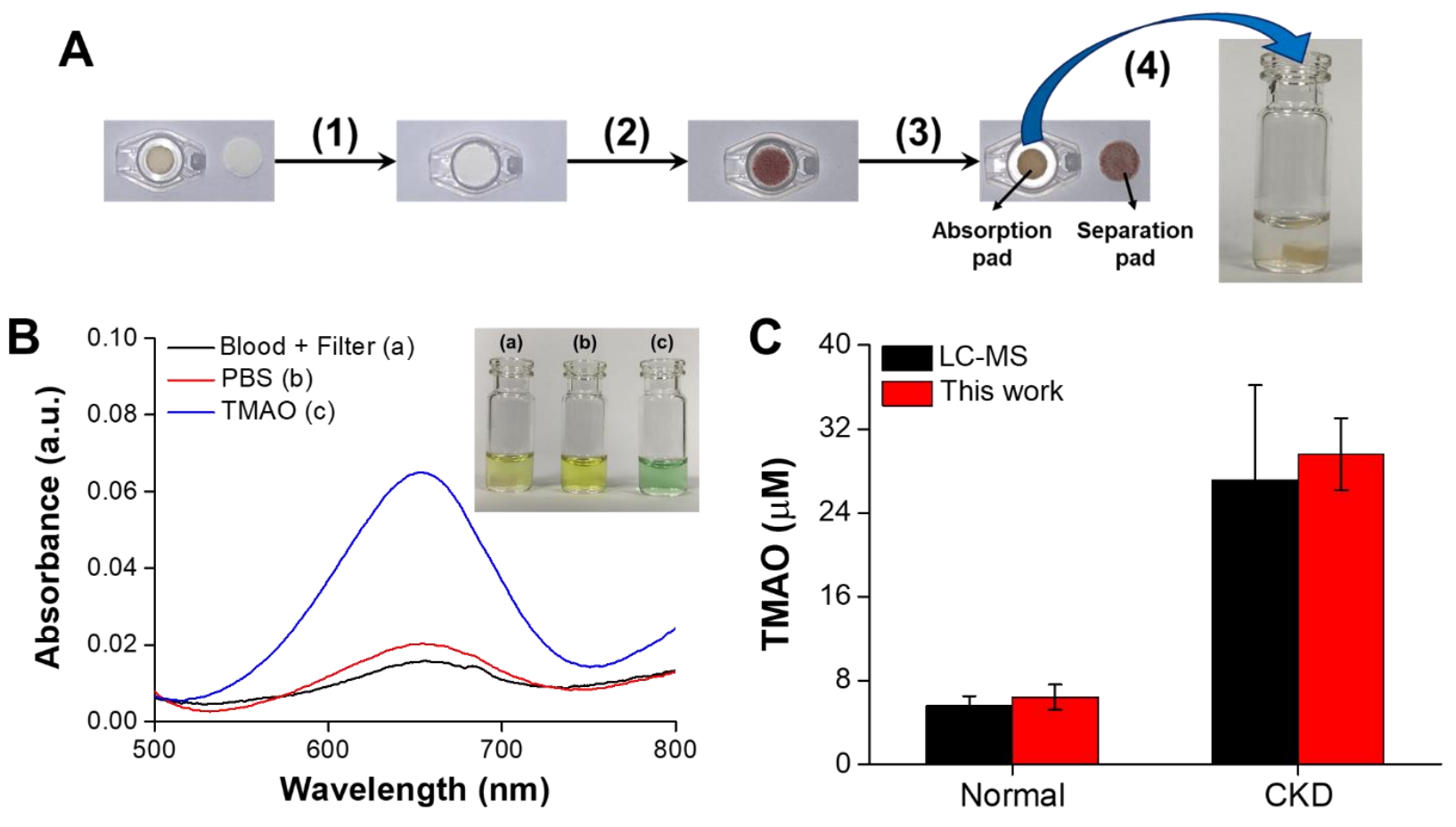

Figure 5. (A) The design and principle of colourimetric TMAO detection using whole blood based on the combination of a plasma separation pad as a erythrocyte trap and an absorption pad as serum/plasma trap to filter erythrocytes and haemachrome as follows: (1) the absorption pad is covered with the separation pad; (2) $50 \mu \mathrm{L}$ of whole blood is dropped on the separation pad; (3) the serum/plasma is collected in the absorption pad and (4) the absorption pad with serum/plasma is placed into a glass vial for TMAO detection; (B) UV-vis absorption spectra and visual colour changes of the catalysed oxidation of TMB in two groups to confirm that the erythrocytes and haemachrome of whole blood could be filtered and that normal serum/plasma would not cause proton depletion, similar to PBS; the inset is a corresponding digital photo; (C) TMAO concentrations in 8 whole blood samples from normal rats and 8 whole blood samples from CKD that were measured using LC-MS and the proposed colourimetric assay for CKD monitoring. The values are means $\pm \operatorname{SD}(n=8)$. 


\section{Conclusions}

We have established a proton depletion method for the "colour-switch" sensing and

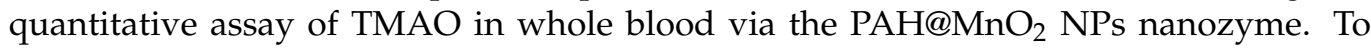
accurately determine concentrations of TMAO in the low $\mu \mathrm{M}$ range for practical diagnostic purposes, a wide linear calibration range of TMAO was successfully established. The feasibility was confirmed by detecting TMAO in whole blood samples from normal rats and CKD rats. In comparison to the previous methods (LC-MS), this proposed colourimetric assay provides a low-cost, easy-to-operate, label-free, rapid and sensitive method for TMAO determination, which may offer an alternative for TMAO detection in clinical studies. This method shows promise for application in tracking TMAO in blood and studying CKD progression in humans in the future.

Supplementary Materials: The following are available online at https:/ /www.mdpi.com/article/10 .3390/bios11090339/s1, Scheme S1: (A) An illustration of PAH@MnO 2 synthesis; (B) the design and principle of colourimetric TMAO detection based on proton deposition of $\mathrm{HCl}$ by TMAO, Figure S1: TMAO concentrations in whole blood from the rats after diet or medication for $24 \mathrm{~h}$ using the proposed colourimetric assay.

Author Contributions: Conceptualisation, Y.-L.T. and H.-W.Y.; methodology, Y.-C.C., Y.-H.C., C.-C.W., C.-H.W., Y.-L.T. and H.-W.Y.; investigation, Y.-C.C., Y.-H.C. and C.-C.W.; resources, Y.-L.T. and H.-W.Y.; data analysis, Y.-C.C., Y.-H.C. and C.-C.W.; data curation, H.-W.Y.; writing-original draft preparation, Y.-C.C., Y.-H.C., C.-C.W., C.-H.W., Y.-L.T. and H.-W.Y.; writing-review and editing, Y.-L.T. and H.-W.Y.; supervision, Y.-L.T. and H.-W.Y. All authors have read and agreed to the published version of the manuscript.

Funding: This work was financially supported by the Ministry of Science and Technology (MOST1092221-E-110-006-MY3), Chang Gung Memorial Hospital, Kaohsiung (CMRPG8K0211), and National Sun Yat-sen University (109-03), Taiwan.

Institutional Review Board Statement: All animal studies were approved by the Institutional Animal Ethics Committee (IACUC) of Chang Gung Memorial Hospital (Permit Number 2020031602).

Informed Consent Statement: Not applicable.

Data Availability Statement: Data is contained within the article.

Conflicts of Interest: No potential conflicts of interest were reported by the authors.

\section{References}

1. Lozano, R.; Naghavi, M.; Foreman, K.; Lim, S.; Shibuya, K.; Aboyans, V.; Abraham, J.; Adair, T.; Aggarwal, R.; Ahn, S.Y.; et al. Global and regional mortality from 235 causes of death for 20 age groups in 1990 and 2010: A systematic analysis for the Global Burden of Disease Study 2010. Lancet 2012, 380, 2095-2128. [CrossRef]

2. Koeth, R.A.; Wang, Z.; Levison, B.S.; Buffa, J.A.; Org, E.; Sheehy, B.T.; Britt, E.B.; Fu, X.; Wu, Y.; Li, L.; et al. Intestinal microbiota metabolism of L-carnitine, a nutrient in red meat, promotes atherosclerosis. Nat. Med. 2013, 19, 576-585. [CrossRef] [PubMed]

3. Xu, K.-Y.; Xia, G.-H.; Lu, J.-Q.; Chen, M.-X.; Zhen, X.; Wang, S.; You, C.; Nie, J.; Zhou, H.-W.; Yin, J. Impaired renal function and dysbiosis of gut microbiota contribute to increased trimethylamine N-oxide in chronic kidney disease patients. Sci. Rep. 2017, 7, 1445. [CrossRef]

4. Liu, X.; Liu, H.; Yuan, C.; Zhang, Y.; Wang, W.; Hu, S.; Liu, L.; Wang, Y. Preoperative serum TMAO level is a new prognostic marker for colorectal cancer. Biomark. Med. 2017, 11, 443-447. [CrossRef] [PubMed]

5. Zeisel, S.H.; Warrier, M. Trimethylamine N-oxide, the microbiome, and heart and kidney disease. Annu. Rev. Nutr. 2017, 37, 157-181. [CrossRef] [PubMed]

6. Smith, J.L.; Wishnok, J.S.; Deen, W.M. Metabolism and excretion of methylamines in rats. Toxicol. Appl. Pharmacol. 1994, 125, 296-308. [CrossRef] [PubMed]

7. Bell, J.D.; Lee, J.A.; Lee, H.A.; Sadler, P.J.; Wilkie, D.R.; Woodham, R.H. Nuclear magnetic resonance studies of blood plasma and urine from subjects with chronic renal failure: Identification of trimethylamine-N-oxide. Biochim. Biophys. Acta Mol. Basis Dis. 1991, 1096, 101-107. [CrossRef]

8. Stubbs, J.R.; House, J.A.; Ocque, A.J.; Zhang, S.; Johnson, C.; Kimber, C.; Schmidt, K.; Gupta, A.; Wetmore, J.; Nolin, T.D.; et al. Serum trimethylamine-N-oxide is elevated in CKD and correlates with coronary atherosclerosis burden. J. Am. Soc. Nephrol. 2016, 27, 305-313. [CrossRef] 
9. Zhao, X.; Zeisel, S.H.; Zhang, S. Rapid Lc-MRM-Ms assay for simultaneous quantification of choline, betaine, trimethylamine, trimethylamine N-oxide, and creatinine in human plasma and urine. Electrophoresis 2015, 36, 2207-2214. [CrossRef]

10. Wang, Z.; Levison, B.S.; Hazen, J.E.; Donahue, L.; Li, X.M.; Hazen, S.L. Measurement of trimethylamine-N-oxide by stable isotope dilution liquid chromatography tandem Mass spectrometry. Anal. Biochem. 2014, 455, 35-40. [CrossRef]

11. Garcia, E.; Wolak-Dinsmore, J.; Wang, Z.; Li, X.S.; Bennett, D.W.; Connelly, M.A.; Otvos, J.D.; Hazen, S.L.; Jeyarajah, E.J. NMR quantification of trimethylamine-N-oxide in human serum and plasma in the clinical laboratory setting. Clin. Biochem. 2017, 50, 947-955. [CrossRef]

12. Buc, J.; Santini, C.L.; Giordani, R.; Czjzek, M.; Wu, L.F.; Giordano, G. Enzymatic and physiological properties of the tungstensubstituted molybdenum TMAO reductase from Escherichia coli. Mol. Microbiol. 1999, 32, 159-168. [CrossRef] [PubMed]

13. Mitrova, B.; Waffo, A.F.T.; Kaufmann, P.; Iobbi-Nivol, C.; Leimkühler, S.; Wollenberger, U. Trimethylamine N-oxide electrochemical biosensor with a chimeric enzyme. ChemElectroChem 2019, 6, 1732-1737. [CrossRef]

14. Yu, H.; Geng, W.C.; Zheng, Z.; Gao, J.; Guo, D.S.; Wang, Y. Facile fluorescence monitoring of gut microbial metabolite trimethylamine N-oxide via molecular recognition of guanidinium-modified calixarene. Theranostics 2019, 9, 4624-4632. [CrossRef]

15. Askim, J.R.; Mahmoudi, M.; Suslick, K.S. Optical sensor arrays for chemical sensing: The optoelectronic nose. Chem. Soc. Rev. 2013, 42, 8649-8682. [CrossRef] [PubMed]

16. Li, Z.; Suslick, K.S. Ultrasonic preparation of porous silica-dye microspheres: Sensors for quantification of urinary trimethylamine N-oxide. ACS Appl. Mater. Interfaces 2018, 10, 15820-15828. [CrossRef]

17. Shmaefsky, B.R. Artificial urine for laboratory testing. Am. Biol. Teach. 1990, 52, 170-172. [CrossRef]

18. Tain, Y.L.; Lee, C.T.; Chan, J.Y.; Hsu, C.N. Maternal melatonin or N-acetylcysteine therapy regulates hydrogen sulfide-generating pathway and renal transcriptome to prevent prenatal $\mathrm{N}(\mathrm{G})$-nitro-L-arginine-methyl ester (L-NAME)-induced fetal programming of hypertension in adult male offspring. Am. J. Obstet. Gynecol. 2016, 215, 636. [CrossRef]

19. Hsu, C.N.; Chan, J.Y.H.; Wu, K.L.H.; Yu, H.R.; Lee, W.C.; Hou, C.Y.; Tain, Y.L. Altered gut microbiota and its metabolites in hypertension of developmental origins: Exploring differences between fructose and antibiotics exposure. Int. J. Mol. Sci. 2021, 22, 2674. [CrossRef]

20. Song, M.; Liu, T.; Shi, C.; Zhang, X.; Chen, X. Bioconjugated manganese dioxide nanoparticles enhance chemotherapy response by priming tumor-associated macrophages toward M1-like phenotype and attenuating tumor hypoxia. ACS Nano 2016, 10, 633-647. [CrossRef]

21. Lee, P.C.; Li, N.S.; Hsu, Y.P.; Peng, C.; Yang, H.W. Direct glucose detection in whole blood by colorimetric assay based on glucose oxidase-conjugated graphene oxide/MnO2 nanozymes. Analyst 2019, 144, 3038-3044. [CrossRef] [PubMed]

22. Jia, X.; Osborn, L.J.; Wang, Z. Simultaneous measurement of urinary trimethylamine (TMA) and trimethylamine N-oxide (TMAO) by liquid chromatography-mass spectrometry. Molecules 2020, 25, 1862. [CrossRef] [PubMed] 